\title{
Novel CYP24A1 Mutation in a Young Male Patient with Nephrolithiasis: Case Report
}

\author{
Jana Jiráčkováa-c Radomir Hyšpler ${ }^{a, c}$ Sumaya Alkanderid \\ Ladislava Pavlíkováa, c Vladimir Palickaa, c John A. Sayer ${ }^{\mathrm{d}-\mathrm{f}}$ \\ aInstitute for Clinical Biochemistry and Diagnostics, Department of Clinical Osteology, \\ University Hospital Hradec Králové, Hradec Králové, Czech Republic; ${ }^{b}$ Department of \\ Gerontology and Metabolism, University Hospital Hradec Králové, Hradec Králové, Czech

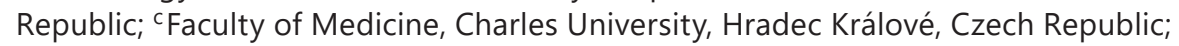 \\ ${ }^{d}$ Institute of Genetic Medicine, Newcastle University, Newcastle, UK; eNewcastle upon Tyne \\ NHS Hospitals Foundation Trust, Newcastle, UK; ${ }^{f}$ NIHR Newcastle Biomedical Research \\ Centre, Newcastle, UK
}

\section{Keywords}

CYP24A1 - Nephrolithiasis · Vitamin D 24-hydroxylase - 1,25-dihydroxy vitamin D3 · Hypercalcemia

\begin{abstract}
Background/Aims: The CYP24A1 gene encodes the vitamin D 24-hydroxylase enzyme, which hydroxylates active forms of vitamin $D$ into inactive forms. Biallelic mutations in the CYP24A1 gene can lead to elevated levels of active vitamin $D$ metabolites and, consequently, to hypercalcemia, hypercalciuria, nephrocalcinosis, and nephrolithiasis; however, monoallelic mutations have been associated only with milder phenotypes. In the present manuscript, we report the case of a young male patient who presented hypercalcemia and nephrolithiasis, suppressed parathormone, and elevated 1,25 dihydroxy vitamin D levels. Methods: Biochemical analyses were performed on Cobas 8000, F. Hoffmann-La Roche AG, Basel, Switzerland. The proband was initially evaluated for occult malignancies by body imaging, serum electrophoresis, and tumor markers, which did not reveal any pathology. DNA samples of the proband and his sibling were then examined using Sanger sequencing. Results: Genetic analysis revealed 2 compound heterozygous CYP24A1 mutations (p.L148P and p.R223*). The novel nonsense CYP24A1 mutation, p.R223*, was also found heterozygously in other family members with a medical history of nephrolithiasis. Conclusions: The identification of this gene mutation causing hypercalcemia, hypercalciuria, and renal stones allows the specific management of endogenous vitamin D production.




\section{Kidney \\ Blood Pressure \\ Research}

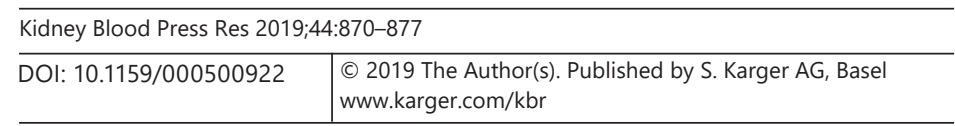

Jiráčková et al.: Novel Mutation in CYP24A1: A Case Report

\section{Introduction}

The CYP24A1 gene encodes a member of the cytochrome P450 superfamily known as vitamin D 24-hydroxylase. This mitochondrial protein is largely present within the intestine and kidneys, catalyzing the hydroxylation of the major active forms of vitamin D, 1,25-dihydroxy vitamin D3 $\left(1 \mathrm{a}, 25[\mathrm{OH}]_{2} \mathrm{D}_{3}\right)$ and 25-hydroxyvitamin $\mathrm{D} 3\left(25[\mathrm{OH}] \mathrm{D}_{3}\right)$, into inactive forms [1]. The latter is a pre-hormone produced in the liver through the enzymatic hydroxylation of cholecalciferol/ergocalciferol (cholecalciferol 25-hydroxylase, CYP2R1) [2], which is then converted into $1 \mathrm{a}, 25[\mathrm{OH}]_{2} \mathrm{D}_{3}$ (by $25[\mathrm{OH}] \mathrm{D}_{3} 1$-alpha-hydroxylase, CYP27B1), a process that mainly occurs in the kidney's proximal tubule [3]. $25[\mathrm{OH}] \mathrm{D}_{3}$ is the precursor of the major active form of vitamin $\mathrm{D}\left(1 \mathrm{a}, 25[\mathrm{OH}]_{2} \mathrm{D}_{3}\right)$; however, it is also capable of activating the vitamin D receptor despite its lower affinity $[4,5]$.

$1 \mathrm{a}, 25[\mathrm{OH}]_{2} \mathrm{D}_{3}$, along with parathormone (PTH) and calcitonin, is an essential regulator of calcium-phosphate metabolism, stimulating calcium and phosphate absorption through the intestines and kidneys in addition to enhancing bone remodeling [6-8]. Further, CYP24A1 is upregulated by $1 \mathrm{a}, 25[\mathrm{OH}]_{2} \mathrm{D}_{3}$, thus ensuring a strict feedback regulation. Loss-of-function mutations in CYP24A1 can lead to elevated levels of $1 \mathrm{a}, 25[\mathrm{OH}]_{2} \mathrm{D}_{3}$ and $25[\mathrm{OH}] \mathrm{D}_{3}$ that can cause absorptive hypercalcemia and hypercalciuria, which leads to complications such as nephrocalcinosis and nephrolithiasis. Calcium deposition in mitochondrial structures and the consequent altered metabolism damage the renal epithelium and provoke tubular necrosis, potentially resulting in chronic kidney disease [9].

The present case report describes a compound heterozygous CYP24A1 mutation in a young male patient and a heterozygous nonsense CYP24A1 in family members affected by renal stone disease.

\section{Case Report}

We report the case of a male Czech patient of Caucasian descent whom initially presented a renal colic at 19 years of age. Renal ultrasonography showed bilateral nephrolithiasis and nephrocalcinosis. Prior to this renal colic episode, the patient had experienced backache and visible hematuria several times after performing sport activities. He did not notice any other health issues. Therapeutic intervention consisted of left-sided extracorporeal shock wave lithotripsy.

A detailed biochemical analysis (Cobas 8000, F. Hoffmann-La Roche AG, Basel, Switzerland) 6 months after the first renal colic episode revealed hypercalcemia (serum calcium levels of $2.87 \mathrm{mmol} / \mathrm{L}$, adjusted for albumin) and hypercalciuria (urinary calcium 11.62 $\mathrm{mmol} / 24 \mathrm{~h}$, urinary ratio calcium/creatinine $0.68 \mathrm{mmol} / \mathrm{mmol}$ ), preserved renal function estimated glomerular filtration rate $\sim 124 \mathrm{~mL} / \mathrm{min} / 1.73 \mathrm{~m} 2$ using chronic kidney disease epidemiology collaboration formula, and suppressed PTH levels $(<0.4 \mathrm{pmol} / \mathrm{L})$. Increased level of $1 \mathrm{a}, 25[\mathrm{OH}]_{2} \mathrm{D}_{3}(226 \mathrm{pmol} / \mathrm{L})$ and $25[\mathrm{OH}] \mathrm{D}_{3}(98.5 \mathrm{nmol} / \mathrm{L})$ within the reference range was found (Table 1). The patient was not under regular medication, had no history of vitamin D or calcium supplementation, no diet or fluid intake abnormalities, and no other dietary supplements or recent history of tanning bed use.

Nephrolithiasis was recurrent and treated by percutaneous nephrolithotomy 3 years later. The chemical analysis of extracted urinary stones revealed calcium phosphate in the form of apatite (50\%) and brushite (45\%).

Given the persistence of hypercalcemia, the proband was initially evaluated for occult malignancies. Body imaging (skeletal scintigraphy, abdomen ultrasonography, and computed chest tomography scan) did not reveal any pathology. Serum electrophoresis and tumor 
Table 1. Characteristics of the proband and his sibling

\begin{tabular}{|c|c|c|}
\hline & Proband & Sibling \\
\hline $\begin{array}{l}\text { Serum calcium, mmol/L } \\
(\text { LRR } 2.15-2.5 \mathrm{mmol} / \mathrm{L})\end{array}$ & 2.87 & 2.74 \\
\hline $\begin{array}{l}\text { Ionized calcium, mmol/L } \\
\text { (LRR } 1.13-1.32 \mathrm{mmol} / \mathrm{L})\end{array}$ & 1.54 & 1.25 \\
\hline $\begin{array}{l}\text { Serum phosphorus, mmol/L } \\
\text { (LRR 0.81-1.45 mmol/L) }\end{array}$ & 0.93 & 1.07 \\
\hline $\begin{array}{l}\text { Serum magnesium, mmol/L } \\
\text { (LRR 0.66-1.07 } \mathrm{mmol} / \mathrm{L} \text { ) }\end{array}$ & 0.82 & 0.88 \\
\hline $\begin{array}{l}\text { Serum creatinine, } \mu \mathrm{mol} / \mathrm{L} \\
\text { (LRR 59-104 } \mu \mathrm{mol} / \mathrm{L} \text { ) }\end{array}$ & 121 & 90 \\
\hline Urinary calcium, mmol/24 h & 11.62 & 5.18 \\
\hline $\begin{array}{l}\text { PTH, pmol/L } \\
\text { (LRR 0.5-6.2 pmol/L) }\end{array}$ & $<0.4$ & 3.6 \\
\hline $\begin{array}{l}25(\mathrm{OH}) \mathrm{D}_{3}, \mathrm{nmol} / \mathrm{L} \\
(\mathrm{LRR} 75-250 \mathrm{nmol} / \mathrm{L}\end{array}$ & 98.5 & 33 \\
\hline $\begin{array}{l}1 \mathrm{a}, 25(\mathrm{OH})_{2} \mathrm{D}_{3}, \mathrm{pmol} / \mathrm{L} \\
(\mathrm{LRR} 60-207 \mathrm{pmol} / \mathrm{L} \text { ) }\end{array}$ & 226 & 126 \\
\hline $\begin{array}{l}\text { ALPbf, } \mu \mathrm{g} / \mathrm{L} \\
(\mathrm{LRR} 5.5-22.9 \mu \mathrm{g} / \mathrm{L})\end{array}$ & 8.6 & 10 \\
\hline $\begin{array}{l}\text { P1NP, } \mu \mathrm{g} / \mathrm{L} \\
\text { (LRR for men under } 30 \text { years not available) }\end{array}$ & 89.36 & Not tested \\
\hline $\begin{array}{l}\text { Beta CTx, } \mu \mathrm{g} / \mathrm{L} \\
\text { (LRR for men under } 30 \text { years not available) }\end{array}$ & 0.917 & Not tested \\
\hline Bone densitometry & $\begin{array}{l}\text { Total } Z \text { score: } \\
\text { Left hip } 0.5 \\
\text { Lumbar spine } 0.5\end{array}$ & Not performed \\
\hline Nephrolithiasis & $\begin{array}{l}\text { Renal colic at } 19 \text { years of age } \\
\text { Present bilaterally (USS) }\end{array}$ & $\begin{array}{l}\text { Renal colic at } 22 \text { years of age } \\
\text { Not present (USS) }\end{array}$ \\
\hline Nephrocalcinosis & Present bilaterally (USS) & Not present (USS) \\
\hline CYP24A1 mutation & p.L148P + p.R223* & p.R223* \\
\hline
\end{tabular}

Basic initial clinical characteristic of the male patient and his sister. The examination was performed in June.

$\mathrm{PTH}$, parathyroid hormone; $\mathrm{ALP}_{\mathrm{bf}}$, alkaline phosphatase - bone fraction; P1NP, procollagen type $1 \mathrm{~N}$ terminal, propeptide; CTx, crosslaps; LRR, lab reference range; USS, ultrasound scan; $1 \mathrm{a}, 25(\mathrm{OH})_{2} \mathrm{D}_{3}, 1,25$-dihydroxy vitamin D3; *, mutation resulting in a premature stop codon.

makers alpha-fetoprotein, carcinoembryonic antigen, C15, C19, and chromogranin - A were within reference range. Bone densitometry (DEXA - dual-energy x-ray absorptiometry) and bone turnover markers were also within the reference range for age, gender, and body mass index (Table 1).

The patient's family history was informative. Both the patient's mother and maternal uncle suffered from nephrolithiasis since their teenage years. The patient's sister (23 years old) underwent an episode of renal colic (with spontaneous passage of a stone, at 22 years of age). 


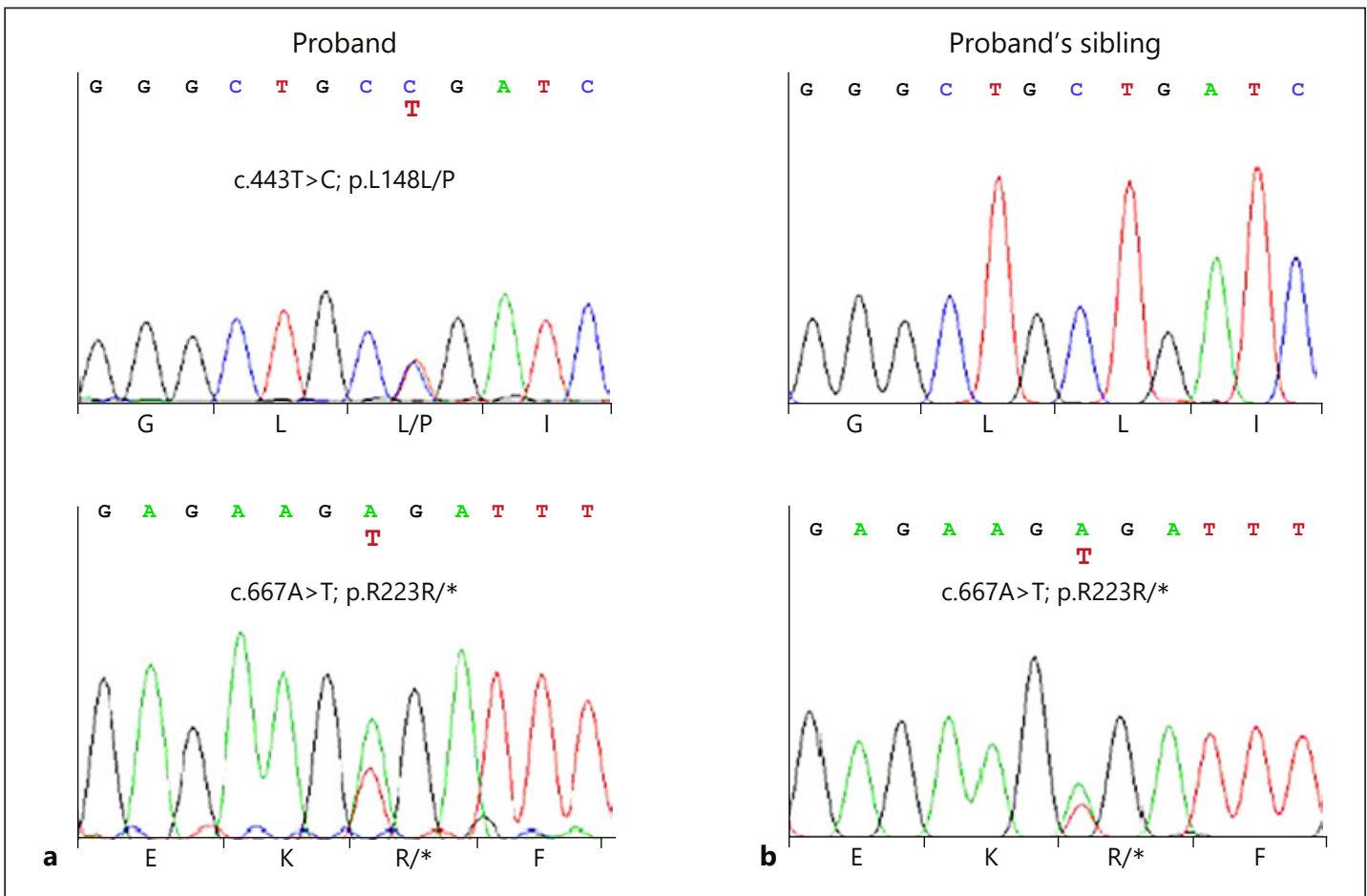

Fig. 1. Sequence chromatograms of the proband and his sister. a Combination of a missense mutation (c.443T>C; p.L148P) and nonsense codon mutation (c.667A>T; p.R223*) in the proband; and (b) novel nonsense mutation (c.667A>T; p.R223*) in its heterozygous state in the proband's sister (reference sequence NM_000782).

Table 2. In silico analysis of CYP24A1 variants

\begin{tabular}{llllll}
\hline & MutationTaster & SIFT & PolyPhen-2 & ExAC & gnomAD \\
\hline c.667A>T p.R223* & Disease causing & NA & NA & 3 het alleles in & 4 het alleles in \\
& & & & 121,400 alleles & 246,230 alleles \\
\hline c.443T>C p.L148P & Disease causing & Deleterious & Probably damaging & 19 het alleles in & 40 het alleles in \\
& & & & 121,306 alleles & 276,994 alleles \\
\hline
\end{tabular}

In silico analysis of $C Y P 24 A 1$ variants.

het, heterozygous; SIFT, sorting intolerant from tolerant; ExAC, the exome aggregation consortium; gnomAD, the genome aggregation database; NA, not applicable; *, mutation resulting in a premature stop codon.

After this episode, occasional hypercalcemia was detected in this sibling (Table 1). The total calcium levels were tested, obtaining the values of 2.74, 2.31, 2.33, and $2.30 \mathrm{mmol} / \mathrm{L}$ in the 6 months period of the study. On the other hand, free calcium levels were estimated in 1.25-1.30 $\mathrm{mmol} / \mathrm{L}$. The patient's father had no health problems related to nephrolithiasis or hypercalcemia.

Following informed written consent, DNA samples of the proband and his sibling were examined using Sanger sequencing. Two compound heterozygous pathogenic mutations in the CYP24A1 gene were identified in the proband; these included a previously reported missense mutation (c.443T>C, p.L148P) and a novel nonsense mutation (c.667A>T, p.R223*). The patient's sister was heterozygous for the nonsense mutation p.R223* and wild type for 
Fig. 2. Family tree of $C Y P 24 A 1$ mutations in the proband's relatives. The proband is marked with an arrow, using black filling to indicate biallelic mutations. The blank symbols represent unaffected persons, whereas a dot symbolizes a heterozygous load.

Fig. 3. Representation of annual calcium level fluctuations in the plasma of the proband. Line A no regime intervention. Line $\mathrm{B}$ with regime intervention.
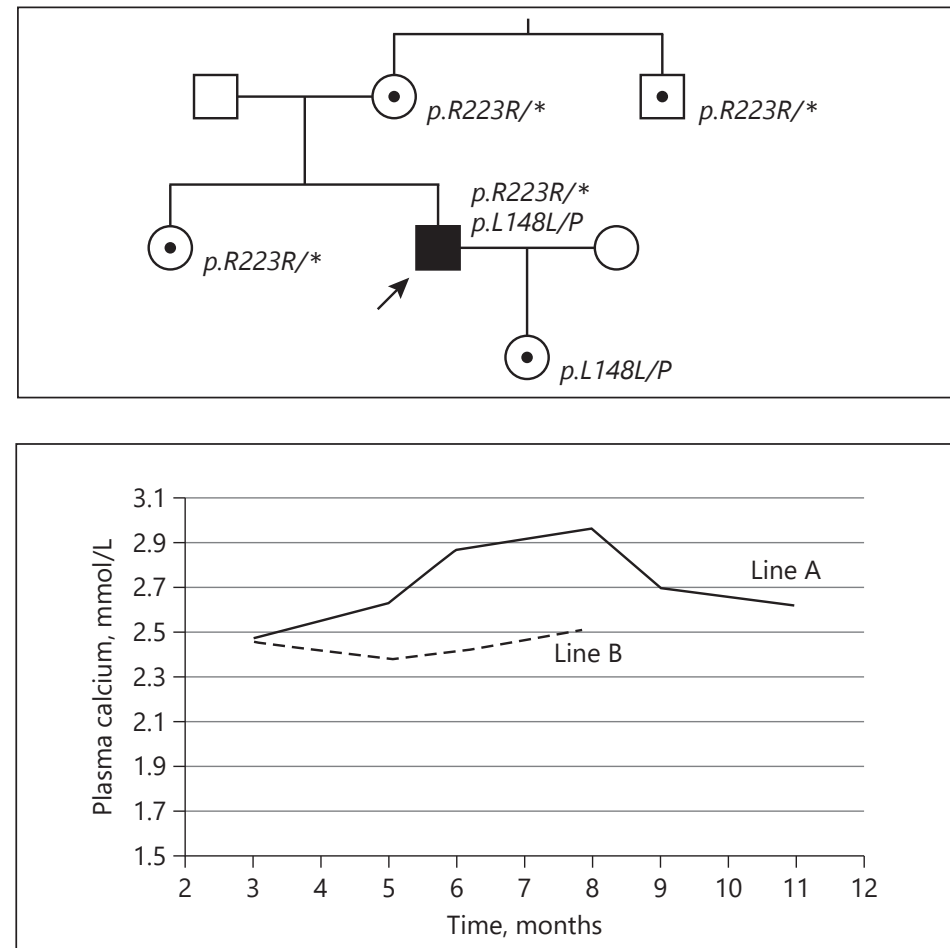

the remaining allele (Fig. 1; Table 2). Segregation analysis revealed that the mutation p.R223* was also present in heterozygous state in the patient's mother and maternal uncle, both of whom had a history of renal stones. The patient's father was wild type for both alleles. Further, the heterozygous missense mutation (p.L148P) was found in the patient's newborn daughter, which also presented a wild-type status for the second allele (Fig. 2).

Serum biochemistry was performed repeatedly in the proband through different seasons of the year. Total serum calcium levels ranged from 2.38 to $2.96 \mathrm{mmol} / \mathrm{L}$ (Fig. 3), with a tendency toward higher levels during summer and becoming lower at the end of winter. We also observed corresponding plasma-level fluctuations of $25[\mathrm{OH}] \mathrm{D}_{3}$ (mean values: [1] without the regime intervention summer $-106.25 \mathrm{nmol} / \mathrm{L}$; [2] with the regime intervention summer/ winter - 97.1/52.35 nmol/L; summer April - September/winter October/March) and $1 \mathrm{a}, 25[\mathrm{OH}]_{2} \mathrm{D}_{3}$ (mean values: [1] without the regime intervention summer - $204.5 \mathrm{pmol} / \mathrm{L}$; [2] with the regime intervention summer/winter-120/98.5 pmol/L; summer April-September/ winter October/March), with the highest values observed during August (summer) and the lowest in February (winter).

The patient was treated empirically with a fluid regimen, restriction of dairy products, and L-methionine $500 \mathrm{mg} 3$ times a day. Consistent use of sunscreens, avoidance of tanning beds, and products containing vitamin D was recommended.

\section{Discussion}

The human CYP24A1 gene encodes a mitochondrial protein of 514 amino acids possessing 23- and 24-hydroxylase activity. This gene is mostly expressed in tissues responsive to $1 \mathrm{a}, 25[\mathrm{OH}]_{2} \mathrm{D}_{3}$, which includes kidneys, intestines, and skin [10-12]. 


\section{Kidney \\ Blood Pressure \\ Research}

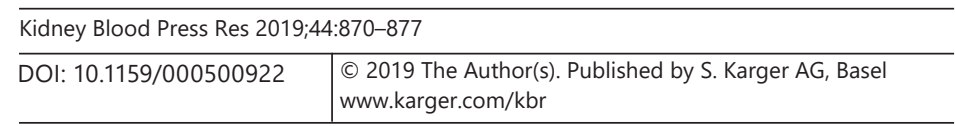

Jiráčková et al.: Novel Mutation in CYP24A1: A Case Report

CYP24A1 mutations cause the reduced function of the vitamin D 24-hydroxylase enzyme, leading to persistent active metabolites of vitamin $\mathrm{D}, 1 \mathrm{a}, 25[\mathrm{OH}]_{2} \mathrm{D}_{3}$ and $25[\mathrm{OH}] \mathrm{D}_{3}$. Increased levels of these active forms of vitamin $\mathrm{D}$ can lead to hyperabsorptive hypercalcemia and hypercalciuria and, consequently, to nephrolithiasis and nephrocalcinosis. Although loss-offunction mutations in CYP24A1 represent a relatively rare metabolic disorder [10], it should always be considered as the underlying cause of calcium nephrolithiasis, especially in young patients with positive family history of nephrolithiasis.

In the present case, the young male patient showed symptoms of hypercalcemia and hypercalciuria, elevated $1 \mathrm{a}, 25[\mathrm{OH}]_{2} \mathrm{D}_{3}$ level, and suppressed $\mathrm{PTH}$, which are the typical biochemical characteristics of patients carrying a loss-of-function mutation in CYP24A1. Although the patient's biochemical characteristics, in addition to the positive family history and the young age of the patient, were indicative of an underlying genetic disorder, more common causes for the increased levels of $1 \mathrm{a}, 25[\mathrm{OH}]_{2} \mathrm{D}_{3}$, such as exogenous supply and endogenous overproduction, should be excluded first. Thus, the patient was carefully interrogated about his diet regimen and supplementation. Further, to exclude an occult malignancy as a potential source of $1 \mathrm{a}, 25[\mathrm{OH}]_{2} \mathrm{D}_{3}$ overproduction, body imaging and serum tumor marker analyses were performed. However, no pathologic result was found and thus there was no indication of exogenous or endogenous cause for the increased levels of $1 \mathrm{a}, 25[\mathrm{OH}]_{2} \mathrm{D}_{3}$.

Accordingly, the prior analyses were followed by sequencing CYP24A1 in search of pathogenic variants. This revealed 2 pathogenic CYP24A1 alleles; the first was a known missense mutation (p.L148P) that results in 25-50\% decreased activity of CYP24A1 [10, 13, 14]. This mutation was found in the patient's newborn daughter as well; however, it was not found in either of the patient's parents. The patient's father presented a wild-type genotype which is consistent with the lack of nephrolithiasis symptoms. Therefore, this CYP24A1 missense mutation (p.L148P) may have arisen de novo or nonpaternity should be considered.

The second CYP24A1 mutation found in the proband was a novel nonsense mutation (p.R223*). This mutation was also found heterozygously in the patient's sister, mother, and maternal uncle. All of these relatives had symptoms of nephrolithiasis since their youth. The patient's sister had evidence of occasional hypercalcemia. Her abdomen ultrasonography did not reveal nephrolithiasis or nephrocalcinosis. The familiar medical history on the maternal side suggests that the novel allele (p.R223*), even in its heterozygous state, may have a significant impact on calcium metabolism and leads to nephrolithiasis.

The hypercalcemia with hypercalciuria causing progressive nephrolithiasis and nephrocalcinosis in our young male patient was caused by compound biallelic CYP24A1 mutations that led to increased activity of the vitamin D metabolite $1 \mathrm{a}, 25[\mathrm{OH}]_{2} \mathrm{D}_{3}$. The management of our patient included:

\section{Biochemical and Body Imaging Monitoring}

Blood samples from the proband were analyzed repeatedly at different seasons of the year; however, regular examination could not be achieved due to poor compliance by the patient. Fluctuations of vitamin D plasma levels during seasonal sunlight exposure were detected, as described previously [15], with the highest values observed during August (summer) and the lowest values during February (winter). Corresponding fluctuations of calcemia were noticed. Further examination by abdomen ultrasonography showed progressive nephrolithiasis.

Bone densitometry was also performed to identify any loss of bone tissue, which is an essential examination tool in patients with calcium/phosphate metabolism disorders. Despite that vitamin D is crucial in sufficient quantity for bone formation and mineralization, high levels can also result in inadequate bone resorption [16]. In addition, basic bone turnover markers were examined, with P1NP and Beta CTx showing a very modest increase (in relation 


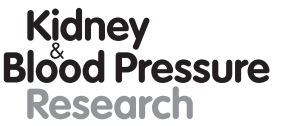

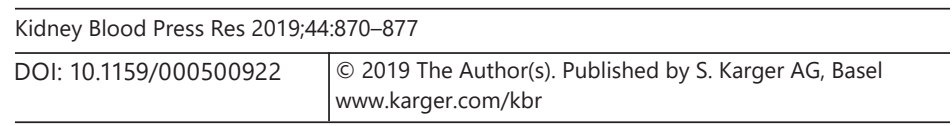

Jiráčková et al.: Novel Mutation in CYP24A1: A Case Report

to the age, gender, and BMD of the patient), DXA showed values entirely within the normal range and the patient had no medical history of bone fractures. Therefore, we suggest that a calcium/phosphate metabolic disorder related to CYP24A1 mutations (p.L148P, p.R223*) does not seem to have a negative influence on bone quality during the young age of the afflicted patient. However, bone quality could be influenced in a positive manner by the active sport habits of the proband, as we know that physical activity contributes markedly to increased bone density [17].

\section{Regimen Arrangement and Medication}

A high fluid intake, avoiding unnecessary sun exposure and tanning beds, and minimization of dietary vitamin D intake was recommended. Supplementation with L-Methionine was recommended for urinary acidification to prevent calcium phosphate stone formation [18].

The successful short-term therapy with azole agents has been described in patients with CYP24A1 mutations for their ability to inhibit cytochrome P450-dependent enzyme systems and thus inhibiting liver metabolism of vitamin D [10,19]. Regardless, long-term therapy with azole agents is not suitable because of its potentially serious side effects, including hepatotoxicity. Recently, encouraging results have shown that low doses of fluconazole could be considered in the treatment of patients with CYP24A1 mutations due to its favorable sideeffects profile $[20,21]$.

\section{Conclusions}

Biallelic mutations in the CYP24A1 gene can lead to elevated levels of active vitamin D metabolites, hypercalcemia, hypercalciuria, and nephrolithiasis. In the present case, the genetic analysis of the CYP24A1 gene in a young male patient revealed 2 compound heterozygous mutations, p.L148P and p.R223*. The latter represents a novel nonsense mutation that was also found in the maternal members of the patient's family, whom also had evidence of renal stone disease. The identification of this molecular genetic cause of renal stones enables the specific management of these patients to minimize endogenous vitamin D production.

\section{Acknowledgment}

The authors would like to thank Dr. Daniel Díaz, PhD, for his assistance in proofreading.

\section{Statement of Ethics}

Ethical approval for this study was provided by Newcastle Upon Tyne Research Ethics Committee. The patients supplied written informed consent for the publication of this case.

\section{Disclosure Statement}

The authors declare no conflicts of interest. 


\section{Kidney \\ Blood Pressure Research}

\begin{tabular}{l|l}
\hline Kidney Blood Press Res 2019;44:870-877 \\
\hline DOI: 10.1159/000500922 & $\begin{array}{l}\text { @ 2019 The Author(s). Published by S. Karger AG, Basel } \\
\text { www.karger.com/kbr }\end{array}$ \\
\hline
\end{tabular}

Jiráčková et al.: Novel Mutation in CYP24A1: A Case Report

\section{Funding Sources}

We acknowledge the support of the Northern Counties Kidney Research Fund and Kidney Research UK (to J.A.S.), Ministry of Health of the Czech Republic grant DRO (UHHK, 00179906, to V.P.), grant TA CR TA04010954 (to R.H.), and by the Charles University research program PROGRES Q40 (to L.P.).

\section{Author Contributions}

J.J., R.H., L.P., and V.P.: performed clinical studies, conceived the study, and wrote the draft. S.A. and J.A.S.: performed molecular genetic analysis. J.A.S.: performed in silico analysis and edited the manuscript.

\section{References}

1 Schlingmann KP, Kaufmann M, Weber S, Irwin A, Goos C, John U, et al. Mutations in CYP24A1 and idiopathic infantile hypercalcemia. N Engl J Med. 2011 Aug;365(5):410-21.

2 Cheng JB, Levine MA, Bell NH, Mangelsdorf DJ, Russell DW. Genetic evidence that the human CYP2R1 enzyme is a key vitamin D 25-hydroxylase. Proc Natl Acad Sci USA. 2004 May;101(20):7711-5.

3 Takeyama K, Kitanaka S, Sato T, Kobori M, Yanagisawa J, Kato S. 25-Hydroxyvitamin D3 1alpha-hydroxylase and vitamin D synthesis. Science. 1997 Sep;277(5333):1827-30.

4 Quesada-Gomez JM, Bouillon R. Is calcifediol better than cholecalciferol for vitamin D supplementation? Osteoporos Int. 2018 Aug;29(8):1697-711.

5 Luxwolda MF, Kuipers RS, Kema IP, van der Veer E, Dijck-Brouwer DA, Muskiet FA. Vitamin D status indicators in indigenous populations in East Africa. Eur J Nutr. 2013 Apr;52(3):1115-25.

6 DeLuca HF. Metabolism of vitamin D: current status. Am J Clin Nutr. 1976 Nov;29(11):1258-70.

7 McSheehy PM, Chambers TJ. 1,25-Dihydroxyvitamin D3 stimulates rat osteoblastic cells to release a soluble factor that increases osteoclastic bone resorption. J Clin Invest. 1987 Aug;80(2):425-9.

8 Maierhofer WJ, Gray RW, Cheung HS, Lemann J Jr, Maierhofer WJ. Bone resorption stimulated by elevated serum 1,25-(OH)2-vitamin D concentrations in healthy men. Kidney Int. 1983 Oct;24(4):555-60.

9 Scarpelli DG, Tremblay G, Pearse AG. A comparative cytochemical and cytologic study of vitamin D induced nephrocalcinosis. Am J Pathol. 1960 Mar;36:331-53.

10 Nesterova G, Malicdan MC, Yasuda K, Sakaki T, Vilboux T, Ciccone C, et al. 1,25-(OH)2D-24 hydroxylase (CYP24A1) deficiency as a cause of nephrolithiasis. Clin J Am Soc Nephrol. 2013 Apr;8(4):649-57.

11 Akeno N, Matsunuma A, Maeda T, Kawane T, Horiuchi N. Regulation of vitamin D-1alpha-hydroxylase and -24-hydroxylase expression by dexamethasone in mouse kidney. J Endocrinol. 2000 Mar;164(3):339-48.

12 Sakaki T, Kagawa N, Yamamoto K, Inouye K. Metabolism of vitamin D3 by cytochromes P450. Front Biosci. 2005 Jan;10:119-34.

13 Jones G, Prosser DE, Kaufmann M. 25-Hydroxyvitamin D-24-hydroxylase (CYP24A1): its important role in the degradation of vitamin D. Arch Biochem Biophys. 2012 Jul;523(1):9-18.

14 Kaufmann M, Prosser DE, Jones G. Bioengineering anabolic vitamin D-25-hydroxylase activity into the human vitamin D catabolic enzyme, cytochrome P450 CYP24A1, by a V391L mutation. J Biol Chem. 2011 Aug; 286(33): 28729-37.

15 Figueres ML, Linglart A, Bienaime F, Allain-Launay E, Roussey-Kessler G, Ryckewaert A, et al. Kidney function and influence of sunlight exposure in patients with impaired 24-hydroxylation of vitamin D due to CYP24A1 mutations. Am J Kidney Dis. 2015 Jan;65(1):122-6.

16 Yoshida T, Stern PH. How vitamin D works on bone. Endocrinol Metab Clin North Am. 2012 Sep;41(3):557-69.

17 Heinonen A, Kannus P, Sievänen H, Oja P, Pasanen M, Rinne M, et al. Randomised controlled trial of effect of high-impact exercise on selected risk factors for osteoporotic fractures. Lancet. 1996 Nov;348(9038):1343-7.

18 Siener R, Struwe F, Hesse A. Effect of L-Methionine on the Risk of Phosphate Stone Formation. Urology. 2016 Dec;98:39-43.

19 Tebben PJ, Milliner DS, Horst RL, Harris PC, Singh RJ, Wu Y, et al. Hypercalcemia, hypercalciuria, and elevated calcitriol concentrations with autosomal dominant transmission due to CYP24A1 mutations: effects of ketoconazole therapy. J Clin Endocrinol Metab. 2012 Mar;97(3):E423-7.

20 Sayers J, Hynes AM, Srivastava S, Dowen F, Quinton R, Datta HK, et al. Successful treatment of hypercalcaemia associated with a CYP24A1 mutation with fluconazole. Clin Kidney J. 2015 Aug;8(4):453-5.

21 Schuster I, Egger H, Bikle D, Herzig G, Reddy GS, Stuetz A, et al. Selective inhibition of vitamin D hydroxylases in human keratinocytes. Steroids. 2001 Mar-May;66(3-5):409-22. 